DOI: 10.1515/ausfm-2018-0007

\title{
Gestural Intermediality in Jean-Luc Godard's First Name: Carmen (1983)
}

\author{
François Giraud \\ University of Edinburgh (United Kingdom) \\ E-mail: F.Giraud@ed.ac.uk
}

\begin{abstract}
Although the intermediality of Jean-Luc Godard's films of the 1980s has been extensively analysed, especially the tableaux vivants in Passion (1982), little has been said on the intermedial dimension of gesture in the director's work of this period. The article investigates how the gestural flows in Godard's First Name: Carmen (Prénom Carmen, 1983) interrelate heterogeneous forms, meanings, arts, and media. The interconnection between the gestures of the musicians who are rehearsing Beethoven's late string quartets and the lovers' gestures, inspired by Rodin's sculptures, gives cohesion to the hybrid aesthetics of the film. Gesture is the element which incorporates, develops, and sets in motion the features of the other arts, not only by creating an in-between space that forges links between media, but especially by exhibiting the process of making itself. Indeed, the relationship between the performing, musical, and visual arts is made visible in the exhibition of the corporeal effort of making (whether it be making music, film, or love) that tends to open the boundaries separating the different arts. The aural and visual qualities of gestures communicate between themselves, generating rhythms and forms that circulate in the continuous flow of moving images. By fostering the analogy between the gesture of carving, of performing music, and of making film, Godard highlights what unites the arts in cinema, while feeding on their differences.
\end{abstract}

Keywords: intermediality, gesture, sculpture, music, sound.

After the end of the New Wave in the late 1960s and a decade of militancy and exploration of video in the 1970s, Jean-Luc Godard returned to cinema in the early 1980s. This period is often considered a return to mythical texts, the great masters of art history, and, to a certain extent, the themes of the New Wave. First Name: Carmen (Prénom Carmen, 1983) is the free adaptation into contemporary France of Prosper Mérimée’s tragic short story Carmen (1845) that inspired Georges Bizet’s famous opéra comique in 1875. While robbing a bank with the help of her gang, Carmen (Maruschka Detmers) falls in love with the watchman Joseph (Jacques 
Bonnaffé). Manipulating her Uncle Jean (Godard himself), a filmmaker living in an asylum, she plans to use the shooting of a film as a ploy to kidnap a rich industrialist. In the meantime, Joseph's fiancée, named Claire (Myriem Roussel) rehearses Beethoven's late string quartets with the Prat Quartet. While Laura Mulvey sees a strong connection between First Name: Carmen and Pierrot le fou (1965), which "was already a version of the Carmen story" (1992, 84), Guy Scarpetta notes a difference of tone between the two films: the horizon of Carmen and Joseph's run is no longer utopia, but manipulation, ratios of power, domination, lies, and ploys $(1985,45)$. However, similarly to Passion (1982), the disenchanted criticism of the pressure of capitalism ${ }^{1}$ is counterbalanced by the filmmaker's attention to the gestures of creation. In a fictional world which is at once violent and chaotic, Beethoven's music, which structures the entire film, becomes a source of gestural exchanges that interconnect the scattered fragments of the editing.

Godard's aesthetics of heterogeneity, which plays with formal contrasts and variations of tempo, combines heterogeneous motifs and media, while mixing contrasting genres (comedy, melodrama, and crime film), acting styles, and tones: "the love story is on the one hand made of elliptical gestures and violent clashes, and on the other intimate moments which combine the poetic with the vulgar," Powrie notes $(1995,66)$. Yet, instead of emphasizing the effects of "dislocation" (Powrie 1995, 64), the film, especially its editing, creates a productive and unifying dialogue between the heterogeneous components which constitute it, such as the musical rehearsals, the pictures and sounds of the sea, and the lovers' gestures inspired by Rodin's sculptures. According to Jacques Rancière, Godard, in First Name: Carmen, works on the mysterious co-presence of the heterogeneous elements which compose the world, including music. ${ }^{2}$ Rather than highlighting their antagonism, he connects them in "the fusion music of images which unite, in one and the same breath, the noises of strings, of waves and of bodies" (Rancière 2004, 81). Although "fusion" is not the most adequate term to qualify Godard's editing and gestural research since the director also emphasizes the interval between

1 The film insistently refers to Godard's militant work of the late 1960s and early 1970s. More than fifteen years after La Chinoise (1967), Godard shows himself dwelling on similar political ideas. Strikingly, both in First Name: Carmen and in an interview for L'Avant-scène cinéma published after its release, Godard uses the same words to criticize the excesses of capitalism. The fictional filmmaker, when talking in the film, strangely echoes the "real" filmmaker when he comments on the same film: "the machines have started to produce goods that don't correspond to any need from atomic bombs to plastic cups" (Prénom Carmen); "as Norman Mailer said, we produce more and more, but useless things: the nuclear bomb and plastic cups" (Godard and Steinebach 1984, 8). All translations are my own unless otherwise stated.

2 According to Rohmer, music in Godard's cinema does not aim to accompany the image, but is filmed as being part of the world, like a tree or the sea $(1998,234)$. 
the heterogeneous elements, the interrelation between the musicians' and actors' gestures generates shared motifs and rhythms. The "linkage of gestures," to use Petra Löffler's expression $(2017,34)$, makes hold together the pieces of the puzzle.

In his well-known essay Notes on Gesture, Giorgio Agamben defines cinema as the exhibition of a "pure gesturality" and the exposure of the "mediality" of gesture (2000, 58-9). Similarly, Godard defines the original form of cinema as a medium "which deals in human gestures and actions (unlike painting or music and dance) in their reproduction" (Godard and Bachmann 1984, 19). Gesture, which must not be confused with action, reveals itself in its corporeal qualities. For example, effort, endurance, dexterity, grace or clumsiness are gestural qualities which manifest the characters' attitude and ethical relationship with the world and others. In this sense, gesture proves to be above all relational and intersubjective. In First Name: Carmen, gesture can be viewed as a means of interaction, not only between the characters and musicians, but also between various media and arts, such as film, music, and sculpture. The crucial role of gesture as a medium of in-betweenness enables us to rethink the concept of intermediality in cinema. According to Ágnes Pethő, intermediality designates an "in-between" space where arts and media circulate and interact. "Cinema seems to consciously position itself 'in-between' media and arts, employing techniques that tap into the multimedial complexity of cinema, exploiting the possibilities offered by the distinctive characteristics of the media components involved in the cinematic process of signification, and bringing into play the tensions generated by media differences." (Pethő 2011, 2.) By drawing on this definition, we can postulate that gesture in film interconnects different media and subjects, interrelates art forms, and highlights the relationship between heterogeneous modes of expression. As Jenny Chamarette suggests, "gesture, in all its philosophical and embodied complexity, offers a means of thinking about intermediality and intersubjectivity, as a migratory, transitory process of meaning-making" $(2013,46)$. She adds that "gesture is $[\ldots]$ what transmits expression, but also the modality through which expression is made perceivable" (Chamarette 2013, 48). Making a film involves not only the interaction of different media, but also of different modes of expression that enter into dialogue and exchange their gestural properties.

In the early 1980s, Godard multiplies intermedial strategies to reflect on the gestural nature of the cinematic image. In Every Man for Himself (Sauve qui peut [la vie], 1980), Godard shows, thanks to the technique of slow motion, the interplay between the mediality of human gestures and the technological body of cinema that mechanically reproduces them. In Passion, Godard stages tableaux vivants 
which, through the models' attitudes and gestures, figurate the tension between painting and cinema. Moreover, at the time of First Name: Carmen's release, Godard is more and more concerned about the issues of the death of cinema and of the crucial role of human gesture in the fabrication and communication of images (Godard and Bachmann 1984, 19; Godard and Steinebach 1984, 8). While praising the "love of the cinema" (Godard and Bachmann 1984, 15), he criticises the power of television that, according to him, fails to really communicate with the spectators and to stimulate their faculty of imagination. He considers television, which is "causing the decline of the images" (Godard and Bachmann 1984, 18), as a lifeless mass ("masse amorphe") that does not address spectators as active subjects (Godard and Steinebach 1984, 8). By contrast, Godard considers the cinematic image as a gestural trace of life, like the traces left on the walls of the caves (Godard and Steinebach 1984, 8). Indeed, far from being only the product of the cinematic machine, moving images are also made by human gestures. As the French philosopher Marie-José Mondzain writes, "a film is a gesture and the objects which form the history of cinema are significant thanks to the gestures they address to the spectator. The image is made by "human hands"' $(2011,25)$. Exploring the gestural potentialities of cinema, Godard attempts to restore the capability of the cinematic image to address the spectator's gaze. Beyond the ontology of cinema, based on the process of mechanical reproduction, the director seeks to communicate the mark of his gestures, and, in order to rethink the craft of filmmaking, develops analogies with the other arts, such as music and sculpture.

First of all, Godard draws on silent cinema to revive film as a gestural form of art. In First Name: Carmen, he develops and highlights the interplay and interval between images, gestures, words, sounds, and music. According to André LeroiGourhan, the perfection of reproduction in talking films and television (unlike in silent cinema) tends to plunge the spectator's perception into a state of passivity that neutralizes his/her effort of interpretation and imagination (1965, 295). Although Leroi-Gourhan's assertion is arguable, as sound in talking pictures, for example, enables filmmakers to develop the off-camera space and explore the boundaries between the visible and the invisible, his argument echoes Godard's criticism of the "terrorism of language," which not only is pervasive in television but also tends to reduce the potentialities of the cinematic image (Godard and Bachmann 1984, 14). In the title First Name: Carmen, the word prénom points to what comes before the name, or, in other words, before language. Godard attempts to show things before they are named by returning to a form of cinema which precedes the advent of talking pictures: "children are going to play Carmen; 
like Chaplin in the old days. Because it is true that it is a silent film. A film which would have become silent with the appearance of talking pictures" (in Lefèvre 1983, 115). In this perspective, Godard's resistance against the dominant use of the audiovisual medium manifests itself in Prénom Carmen through the relationship between the image and the music, and more broadly the soundtrack. The combination of heterogeneous artistic forms and the hybridization of the audiovisual medium foster the spectator's active reception. The coordination of the musicians' and characters' gestures creates what Deleuze names a "pluridimensional, pictorial and musical gest” $(1989,195)$. Godard weaves a complex network of gestures in order to compose the film, from the rehearsals of the string quartet to the visual and sonic bodily attitudes of the lovers, inspired by Rodin.

In First Name: Carmen, gesture makes the corporeal effort of making, working, and performing visible and audible. Far from being only visual, gestures produce sounds, noises, rhythms, and music, which resound in space and time. At the beginning of the film, when Uncle Jean makes the objects of his hospital room resound, the director invites us to consider gesture not only in its visual but also aural qualities. Like a blind man, he frantically and noisily touches the windowpanes, as well as other objects, such as the bed, the typewriter, and his own body. As Deleuze writes on Godard's cinema, "the body is sound as well as visible” $(1989,193)$. The filmmaker shows his ability to manipulate and design the sounds which, in the sequence described above, have a particular resonance and precision, as if the author had carefully selected, isolated, and intensified them. Michel Chion analyses how filmmakers usually emphasize the sounds of gestures and "give noise to the body through sound effects" by recreating the sounds in real life and giving them a "rendering" adapted to the cinema (2009, 237). Although Godard uses direct sound (Fox 2018, 67), he stresses the musicality of gestures by revealing the percussive and sonic potentiality of the human body. Jennifer M. Barker defines a sonic body, not as a body that makes sound, but as a body which "resounds" $(2013,252)$. When the sound propagates in space, it resounds within and outside the body. In the film, the sounds (including the waves, Beethoven's music, or even the bursts of gunfire) resound from one image to another. As Carrie Noland points out, the trace of gesture can be unfixed and migrate from one site of performance, one medium and/or one body to another (2008, 16). In First Name: Carmen, the sound trace of gestures is detached from their visual trace, and is connected to other visual and/or sound elements in the editing.

In this way, the editing makes the resonance between the music and the actions of the narrative visually and audibly perceptible. Inspired by the collaboration 
between Eisenstein and Prokofiev in Alexander Nevsky (1938), ${ }^{3}$ Godard wrote the script and shot a large part of the sequences in accordance with Beethoven's late string quartets, which are played in chronological order (the quartets 9, 10, 14, 15, and 16) and developed in the continuity of the sequences (Godard and Bachmann 1984, 16). Strikingly, in the script, the filmmaker has described each sequence by referring to the tone, the tempo, and the musical intentions of the quartets (see Godard, 1985). Music becomes a model of composition ("modèle compositionnel") which enables Godard to envision the actors' gestures (Scarpetta 1985, 48). For example, Godard explains that "the attack on the bank came to be after [he] heard a certain part of the 10th Quartet" (Godard and Bachmann 1984, 16). When he edits the attack of the bank in parallel with the Prat Quartet's rehearsal, the filmmaker connects the act of shooting to the musical performance which is accompanying the on-going action in a distancing effect (the musicians' gestures are at once linked to the images of the bank robbery and kept at a distance, in a separated time-space). At the beginning of the sequence, Godard creates a subtle match cut between the movement of Joseph's rifle, which is waved in all directions, and the bow, which attacks the strings of the violin. Godard establishes intermedial equivalences between the script and the music score, between the musical rehearsal and the shooting of the film, between the rhythm of the musical phrase and the rhythm of the editing, and between the musical instrument and the actor's body. By interweaving the musicians' and the characters' gestures, Godard creates a choreography which simultaneously shapes the visual and aural perception of the quartet's performance and of the action taking place in the bank. Creative and destructive gestures are in dialogue with one another in a ballet of waving arms; the noise of gunshots, typical of $\mathrm{B}$ movies, contrasts with the elevated style of Beethoven, while the indications of the first violinist, insisting on the violence of the musical phrase, heighten the energy of the shooting scene. On several occasions, the musicians stop playing, comment upon their performance, and try to improve it by reworking some parts of the piece: "there it becomes much more tragic;" "it must be more violent;" "the tempo was a bit slack." Such recommendations, which they annotate on their score, determine the colour, the mood, the energy, and the rhythmic sensitivity of the musical phrase and of the cinematic sequence. Similarly to the actors, who need to make gestures appropriate to the meaning and/or form that the director wants to convey, the musicians adapt their gestures to the musical intention that the conductor wants to achieve.

3 For a detailed analysis of Eisenstein's influence on First Name: Carmen, see Fox $(2018,75-81)$. 
According to Deleuze, Godard succeeds in creating a pluri-dimensional and musical gestus. Drawing on Brecht, Deleuze uses the term gestus to name the linkage, interconnection, and coordination of heterogeneous attitudes and gestures (1989, 192). Deleuze's definition of gestus evokes the concept of hypergesture, which has been theorized by Guerino Mazzola in free jazz (2009, 79-87). Hypergesture refers to the dialogue of disparate gestures in a musical performance. In the Prat Quartet's performance, for example, the movement of the violinist's elbow communicates with the cellist's arm and hand gestures, despite their physiological dissimilarities. [Fig. 1.] Their posture and gestural techniques adapt to the shape of their respective instruments. "Hypergesture results [...] from the subjective resonances that humans perceive between physiologically different gestures," Citton explains (2012, 55). The concept highlights the intersubjective dimension of gestures which, rather than being isolated, achieve something in common, through interpersonal relations, exchanges, resonances, dialogue, affective linkage, and collaboration. In First Name: Carmen, the musical gestus, as Deleuze notes, coordinates the couple's and the musician's respective gestures: "the rehearsals of the quartet are not limited to developing and directing the sound qualities of the image, but also the visual qualities, in the sense that the curve of the violinist's arm modifies the movement of the bodies which are embracing" $(1989,195)$. As the script proves, Godard intended to create an effect of resonance between the curved movements of Claire's arm when she bows up and down in sequence 10, and the curved movement of Carmen's arm when she embraces Joseph in sequence 11 (Godard 1985, 565). Besides, contradictory gestures of attraction and rejection structure the lovers' relationship. When Joseph approaches Carmen, she rejects him; when Joseph keeps at a distance, she attracts him. In a scene, Carmen says to Joseph "tirez-vous, attirez-moi” (get out, catch me) rejecting Joseph (re-pousser), and then attracting him (at-tirer). In French, when a violinist pushes the bow up or pulls the bow down, he or she pousse or tire the bow. In that sense, the dialectical movement of attraction and rejection that animates the couple's gestures is directly connected to the musicians' gestures of bowing.

Finally, Godard also coordinates Beethoven's music and the lovers' gestures with the sounds of the sea, while developing an analogy with the gesture of carving. "Godard has likened his method of working with sound in Prénom Carmen to that of a sculptor," Fox explains (2018, 71). In the preparation documents of First Name: Carmen, Godard juxtaposed some reproductions of Rodin's sculptures with Beethoven's quotes. He also asked the cinematographer Raoul Coutard, as well 
as the actors, to see Rodin's work. Facing their lack of interest, as he repeated in several interviews, he eventually gave up the idea of imitating his sculptures. "Take Rodin, the sculptor. In the planning stage of Prénom: Carmen, we had love scenes, which in the end did not become real love scenes in the film, and we wanted to make them like certain Rodin sculptures. In the end the actors didn't like the idea and we didn't do it like that, but we continued to call the love scenes 'the Rodin scenes." (Godard and Bachmann, 17.) Nevertheless, Godard felt the sculptural aspect of the film while editing and mixing the sound: "the sculptor works with two hands against a surface, he carves space, and since musicians are always speaking of audible space I think that the thing I'd like to lead them to do is to carve this audible space" (Godard and Bachmann, 17). By superimposing the sound of the sea and the lovers' bodies, the filmmaker carves the spectator's perception of gestures through editing. If editing and sound are crucial elements to understand the influence of sculpture in the film, Rodin's expressive gestural approach is also visible in the mise-en-scène, in Coutard's work on lighting, which underlines the volumes and angles of the body, in the actors' gestures, and in the shots of waves.

Throughout the film, Godard inserts shots of waves which, like a life force, constantly revitalize the movement of the sea. [Fig. 2.] According to Ágnes Pethó, the filmmaker uses the metaphor of ebb and flow in his cinema to stress the idea that "the blank screen becomes the shore of a cinematic ocean where the waves can be either images or sounds" (2011, 280). In First Name: Carmen, the cinematic screen becomes the in-between space where gesture generates rhythms, forms, and traces, which circulate in the continuous flow of sounds and moving images. The images and sounds of the sea echo not only the choreography of the string quartet - the musicians continuously draw the bow up and down, creating a tide-like swaying movement that circulates between them - , but also Rodin's sculptures. In his well-known essay on the French sculptor, Rilke compares gestures to rushes of water (jaillissement), waves, and backwash (see Gheerardyn 2015). He observes how the gesture in The Age of Bronze (L'Âge d'airain, 1877) "bursts forth like a spring that softly ripples over this body" (Rilke 1946, 21). The expressivity of the sculpted gestures evokes the fluid movement of water and the swell. In First Name: Carmen, the opening shot starts with Carmen saying in voice-over: "it makes terrible waves in me, in you." In the "Rodin scenes," the dialectical movement of ebb and flow echoes the couple's gestures of rejection and attraction. The water retreats in an inward movement and then springs forwards and outward, in the same way that the characters' gestures externalize their inner contradictory feelings and emotions. For instance, during the sequence in Uncle 
Jean's flat, after Carmen rejects Joseph's gestures by pushing him off screen, the man's hand suddenly springs from the off-field space and grips the woman's shoulder. [Figs. 3-4.] The jaillissement is emphasized by the way Godard turns off the diegetic sounds in favour of Beethoven and the sound of the waves. The sudden and silent apparition of Joseph's hand enables the spectator to perceive the emergence of the gesture in the frame. The way that Godard isolates the character's hand evokes Rodin's technique of fragmentation which tends to emphasize "a body's specific gesture" (Steinberg 2007, 362). Rodin sculpted 150 single hands, detached from the rest of the body, which condense "the sum of gestures which a whole body can make” (Steinberg 2007, 339). Then, after having inserted a shot showing the surging of the waves, Godard repeats the exact same take, but instead of editing Beethoven's music, mixes the sounds of the sea with Carmen and Joseph's dialogue. Again, Joseph's hand springs from the off-camera space and grips her shoulder, while she says: "you're attracted to me.” Similarly to the sculptor who works the forms with his two hands, Godard uses only two mixing tracks because he has "only two hands to manipulate them" (Godard and Bachmann 1984, 16). While the characters' gestures echo the continuous sound of the waves, the cinematic process of repetition contributes to carving the spectator's perception of movement in two different ways.

The metaphor of the gesture of carving proliferates in the film. The filmmaker uses the sculptural motif to forge links between the images of the quartet, of the sea, and of the couple, and the editing to create associations, metaphors, and equivalences. "The view of a violin which is carving [the audible space]" is associated with the "image of the sea which does the same, carving with waves and crevasses, highs and lows," and finally with the image of the lovers "who will have moments of high and low feeling." Such a manner of constructing the film and creating cohesion defines cinema according to Godard: "this is how it all hangs together, completely logically, that's the cinema” (Godard and Bachmann 1984, 17). It is through these gestural dynamics of interrelation and intermediality that Godard, as a filmmaker, seeks to actively stimulate the spectators' imagination.

Through the intermedial relationship between cinema and the other arts, Godard roots the media of moving images and the practice of filmmaking in the framework of art history. In this perspective, gesture appears as a central element in the analysis of intermediality in First Name: Carmen, and more broadly in Godard's cinema. When the filmmaker insists on the interplay between the musicians' and the actors' gestures, who work in different places and times, he draws our attention to the craft of filmmaking. Cinema is indeed a hypergestural 
form of art involving the close collaboration of multiple artists, technicians, performers, the interplay of different media and arts, and the coordination of a plurality of technical and artistic gestures, from the writing, the preparation, and the shooting to the editing and the mixing of the film. If a film mechanically reproduces the actors' and performers' gestures, it also communicates, more indirectly, the invisible trace of all the creative gestures which crucially forge its style. In conclusion, we can thus expand Agamben's definition of gesture in cinema by arguing that Godard's cinema exhibits the intermediality of gestures. One the one hand, they interact with the technological body of film, and on the other, incorporate and develop the features of the other arts.

\section{References}

Agamben, Giorgio. 2000. Notes on Gesture. In Means without End. Notes on Politics, 48-59. Minneapolis, London: University of Minnesota Press.

Barker, Jennifer M. 2013. Sonic Bodies. Listening as Acting. In Theorizing Film Acting, ed. Aaron Taylor, 243-55. New York: Routledge.

Chamarette, Jenny. 2013. Between Women: Gesture, Intermediality and Intersubjectivity in the Installations of Agnès Varda and Chantal Akerman. Studies in European Cinema vol. 10, no. 1: 45-57.

Chion, Michel. 2009. Film, a Sound Art. New York, Chichester: Columbia University Press.

Citton, Yves. 2012. Gestes d'humanités. Anthropologie sauvage de nos expériences esthétiques [Gestures of Humanities. Wild Anthropology of Our Aesthetic Experiences]. Paris: Armand Colin.

Deleuze, Gilles. 1989. Cinéma 2. The Time-Image. Minneapolis: University of Minnesota Press.

Fox, Albertine. 2018. Godard and Sound. Acoustic Innovation in the Late Films of Jean-Luc Godard. London, New York: I.B. Tauris.

Gheerardyn, Claire. 2015. Geste révélé, geste révélateur: Rilke face à Rodin [Revealed Gesture, Revealing Gesture: Rilke Facing Rodin]. http://www.fabula. org/colloques/document2666.php. Last accessed 30 May 2018.

Godard, Jean-Luc. 1985. Prénom Carmen: scénario. In Jean-Luc Godard par JeanLuc Godard [Jean-Luc Godard by Jean-Luc Godard], ed. Alain Bergala, 557-73. Paris: Edition de l'étoile.

Godard, Jean-Luc and Gideon Bachman. 1984. The Carrots are Cooked: A Conversation with Jean-Luc Godard. Film Quarterly vol. 37, no. 3: 13-19. 
Godard, Jean-Luc and Sylvie Steinebach. 1984. Les Signes du mal à vivre. Entretien avec Jean-Luc Godard [The Signs of mal à vivre. Interview with JeanLuc Godard]. L'Avant-scène cinéma no. 323-324: 4-11.

Lefèvre, Raymond. 1983. Avant le nom (le langage) des enfants jouent à Carmen [Before the Name (the Language) Children Play Carmen]. In Jean-Luc Godard, 115-116. Paris: Edilig.

Löffler, Petra. 2017. Gesturing the Image. The Chain-Linking of Gestures in JeanLuc Godard's Passion. In Gestures of Seeing in Film, Video and Drawing, eds. Asbjørn Grønstad, Henrik Gustafsson, Øyvind Vågnes, 31-43. New York: Routledge.

Mazzola, Guerino B. 2009. Geometry of Gestures. In Flow, Gesture, and Spaces in Free Jazz. Towards a Theory of Collaboration, eds. Guerino B. Mazzola and Paul B. Charlin, 79-87. Berlin: Springer-Verlag.

Mondzain, Marie-José. 2011. Images (à suivre): de la poursuite au cinéma et ailleurs [Images (to Follow): On Pursuit in Cinema and Elsewhere]. Paris: Bayard.

Noland, Carrie. 2008. Introduction. In Migrations of Gesture, eds. Carrie Noland and Sally Ann Ness, IX-XXVII. Minneapolis, London: University of Minnesota Press.

Mulvey, Laura. 1992. The Hole and the Zero. The Janus Face of the Feminine in Godard. In Jean-Luc Godard. Son+Image, 1974-1991, eds. Raymond Bellour and Mary Lea Bandy, 75-88. New York: The Museum of Modern Art.

Pethő, Ágnes. 2011. Cinema and Intermediality: The Passion for the In-Between. Newcastle upon Tyne: Cambridge Scholars Publishing.

Powrie, Phil. 1995. Godard's Prénom Carmen (1984), Masochism, and the Male Gaze. Forum for Modern Languages Studies vol. 31, no. 1: 64-73.

Rancière, Jacques. 2009. Aesthetics and its Discontents. Cambridge and Malden, MA: Polity Press.

Rilke, Rainer Maria. 1946. Rodin. London: Grey Walls Press.

Rohmer, Eric. 1998. De Mozart en Beethoven, Essai sur la notion de profondeur en musique [From Mozart to Beethoven, Essay on the Notion of Depth in Music]. Arles: Actes Sud.

Scarpetta, Guy. 1985. Docteur, est-ce que l'âme a un corps? [Doctor, Does the Soul Have a Body ?]. Art Press special issue no. 4: 42-50.

Steinberg, Leo. 2007. Rodin. In Other Criteria: Confrontations with TwentiethCentury Art, 322-403. Chicago, London: University of Chicago Press. 


\section{List of Figures}

Figures 1-2. First Name: Carmen: The images and sounds of the sea echo the tide-like swaying movement of the bows as the musicians play.
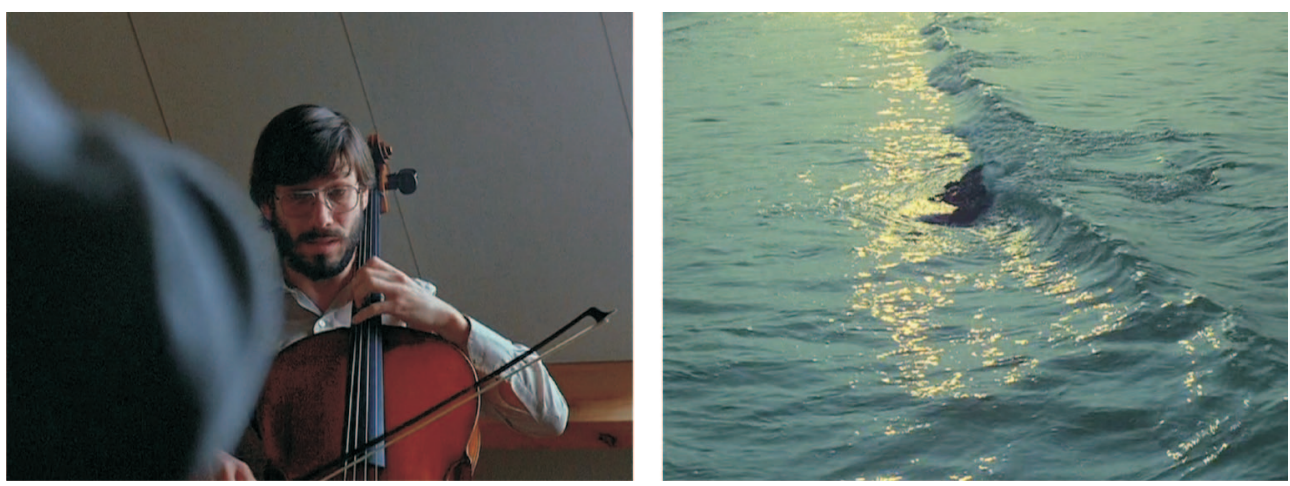

Figures 3-4. First Name: Carmen: the emergence of the gesture in the frame.
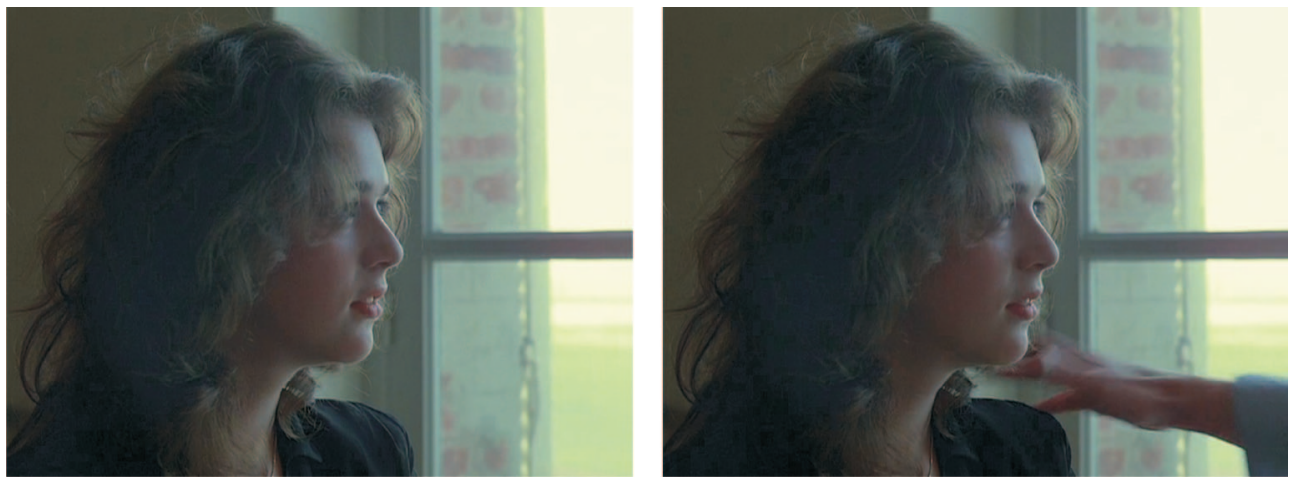